\title{
EVALUATION OF ECOLOGICAL PROTECTION LEVEL UNDER THE FRAMEWORK OF TERRITORY SPATIAL PLANNING OF FUJIAN PROVINCE
}

\author{
Xiaonan Niu ${ }^{1, *}$, Guoguang Chen ${ }^{1}$, Dingyuan Zhang ${ }^{1}$, Jing Zhang ${ }^{1}$, Jie Zhang ${ }^{1}$ \\ ${ }^{1}$ Nanjing Centre, China Geology Survey, Nanjing, 210016, China-niuxiaonan@mail.bnu.edu.cn, cguoguang@126.com, \\ tdr6678@sina.com, zjhfut@163.com,nora_0033@163.com
}

\section{Commission III, WG III/10}

KEY WORDS: Ecological Protection Level, Ecological Protection Red Line, Ecosystem Service Functions, Ecological Sensitivity, Fujian Province

\begin{abstract}
:
A key mission of "the carrying capacity of natural resources and the suitability of territory spatial development evaluation" in China is to carry out the assessment of the ecological protection level, which is based on the ecosystem service functions level and ecological sensitivity level. The evaluation of ecological protection level is the basis for demarcating the ecological protection red line, which has become a major strategy to promote the construction of national ecological civilization. In this paper, taking the whole land area of Fujian province as an example and using the quantifying index method, based on remote sensing data including NPP, NDVI, and land use data, we first assess the ecosystem service functions level and ecological sensitivity level, combined with the existing nature reserves and national forest parks in Fujian province, and then evaluate the ecological protection level. The result shows that, the extremely important ecological protection area is $37,134.68 \mathrm{~km}^{2}$, accounting for $30.59 \%$ of total study area; the area of farmland located in the extremely important ecological protection area is $2,191.56 \mathrm{~km}^{2}$, making up $14.44 \%$ of the total farmland area; the area of construction land within the extremely important ecological protection area is $542.65 \mathrm{~km}^{2}$, accounting for $12.94 \%$ of the total construction land area .
\end{abstract}

\section{INTRODUCTION}

The Ecological Red Line policy is implemented across China, which has played a pivotal role in curbing the disorderly expansion of built-up areas, while conserving ecological integrity. (Hu et al.,2020). It aims to demarcate the border and calibration of the "red line" regions with important ecological functions, which is the basis for the preparation of the territorial spatial planning. In December 2016, the General Office of the Central Committee of the Communist Party of China and the General Office of the State Council jointly issued the "Provincial Spatial Planning Pilot Program" (hereinafter referred to as the "Pilot Program"), and proposed the scientific determination of "three zones and three lines", namely, urban, agricultural, ecological space, and the ecological protection red line, permanent basic farmland, and urban development boundaries, which are used as a carrier to form the spatial planning basemap. The demarcation of "three zones and three lines" begins with carrying out resource and environmental carrying capacity assessment and suitability assessment (hereinafter referred to as "double assessment"). By selecting scientific and reasonable factors and calculation methods, the spatial scope is identified, and a "three zones and three lines" plan is formed, which can provide demonstrations for "multiple planning integration" and the establishment and improvement of the land space development and protection system (Fan, 2019). According to the requirements of the "Pilot Program", the determination of ecological protection red line must be based on the "double evaluation". Through the evaluation of the ecosystem service functions level and ecological sensitivity level, the ecological protection level is estimated. Based on the assessing results, the spatial connectivity evaluation of the ecological candidate area is evaluated, and the ecological protection priority area is selected.
Incorporating and integrating other ecological protection sites, ecological protection red line is formed.

Some studies discussed and practiced the related theories and evaluation methods for the demarcation of the ecological protection red line (Liu, 2012, Jiang et al.,2015, Ding et al., 2016, Yan et al., 2014, Yu et al.,2009, Zhang et al.,2019, Yang et al.,2016). The overall characteristic is to combine the social and natural ecological background of the study area, select the appropriate evaluation perspective, and delineate the ecological protection red line. The evaluation scale ranges from counties to provinces. The evaluation perspective mainly focuses on the ecological function, ecological sensitivity, environmental disaster risk, ecological service maintenance, and other aspects. Evaluation factors involved in ecological functions, ecological values, natural geographical conditions and disaster risks. In addition, the establishment of an ecological security pattern that is derived from landscape security "source-sink theory" has a similar role to the red line for ecological protection. This method was proposed from the perspectives of ecological service value, ecological maintain, and ecological sensitivity. Ecological sources which needs to protect is demarcated and ecological corridors are built. These studies have provided valuable experience for evaluating the ecological protection level and identifying the ecological protection red line. Due to the fact that the researching work of "double assessment" was carried out two years ago, so there are not plenty of studies focusing on it. Among these research methods, the quantifying index method issued by the Ministry of Environmental Protection of China is based on a popular and scientific model using remote sensing data. Several studies related to ecological security and ecological function regionalization refer to this method.

\footnotetext{
* Corresponding author
} 
In this paper, taking the total area of Fujian province as the research area, we use the quantifying index method based on remote sensing data including NPP (Net primary productivity), land use/cover data, DEM, etc. First, we evaluate the ecosystem service function level and ecological sensitivity level, which are combined to obtain an initial result of ecological protection level. Then we use the existing nature reserves, national forest parks, Wuyishan forest park, national wetland parks, and national geological parks of Fujian province to revise the initial result. Last, we get the ecological protection level result including extremely important level, very important level and important level. Based on the results, we analyse the ecological environment conditions of Fujian province, hoping to provide scientific reference for the determination of ecological protection red lines.

\section{METHODS}

\subsection{Study Area}

Fujian province is located on the southeast coast of China, with latitude $23^{\circ} 30^{\prime} \mathrm{N}-28^{\circ} 30^{\prime} \mathrm{N}$ and longitude $116^{\circ} \mathrm{E}-120^{\circ} 30^{\prime} \mathrm{E}$. Fujian province has jurisdiction over 9 prefecture-level cities, and the total area is 12.14 million hectares, as shown in Figure1. It faces the mountains and the sea. The landforms are mainly mountainous and hilly, accounting for more than $80 \%$ of the total area of the province. The regional differences in ecological environment are obvious, and landscape is fragment and complex (Zeng, 2003), forming a feature of abundant and widely distributed vegetation in the territory. Fujian province is located in a subtropical monsoon climate zone, with a warm climate, abundant rainfall, and dense river networks.

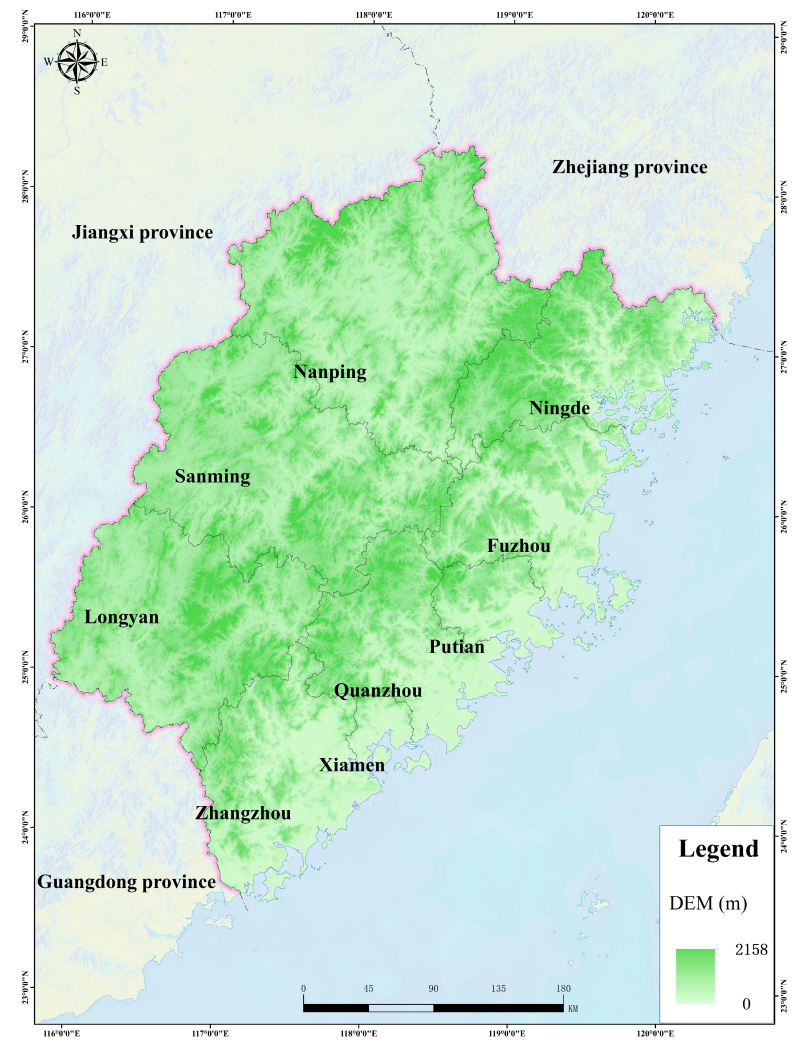

Figure1. The administrative map of Fujian province

\subsection{Data Source and Processing}

The data used in this paper include administrative map of Fujian province, land use data, national geographic census data, NDVI data, NPP data, soil attribute data, DEM data, meteorological data (temperature, precipitation), etc.

As shown in Table1, the DEM data is SRTM terrain data with a spatial resolution of $30 \mathrm{~m}$ downloaded from the geospatial data cloud website. The administrative map of Fujian province are vector data from the Atlas of Natural Resources of Fujian province. The meteorological data are derived from the annual data set of 600 surface meteorological observation stations in Fujian province from 2010 to 2019 of Chinese meteorological science data, including data such as temperature and precipitation. The meteorological data are calculated from the annual average temperature and annual precipitation data using the kriging method. The NPP data are derived from MODIS MOD17A3.The NDVI data are from MODIS NDVI MOD13Q1 data provided by the United States Geological Survey (USGS) with a time resolution of $16 \mathrm{~d}$ from 2001 to 2018. The 2016 national geographic census data provides more detailed vegetation types. The soil data is derived from 1: 1000000 soil data provided by Second National Soil Survey with GRID format and spatial resolution of $1 \mathrm{~km}$. The main fields of the soil attribute table include SU_SYM90 (soil name in FAO90 soil classification system) and T USDA TEX (USDA soil texture classification). Land use data are obtained from national land use change survey data.

\begin{tabular}{|c|c|c|c|}
\hline Data type & Data name & $\begin{array}{l}\text { Data } \\
\text { format }\end{array}$ & Data source \\
\hline $\begin{array}{l}\text { topographic } \\
\text { data }\end{array}$ & DEM & $\begin{array}{l}\text { geotiff } \\
(30 \mathrm{~m})\end{array}$ & $\begin{array}{c}\text { Geospatial } \\
\text { data cloud } \\
\text { website } \\
\end{array}$ \\
\hline $\begin{array}{l}\text { administrative } \\
\text { division data }\end{array}$ & $\begin{array}{l}\text { administrative } \\
\text { division data }\end{array}$ & vector & $\begin{array}{c}\text { Atlas of } \\
\text { natural } \\
\text { resources of } \\
\text { Fujian } \\
\text { province }\end{array}$ \\
\hline \multirow{2}{*}{$\begin{array}{l}\text { meteorological } \\
\text { data }\end{array}$} & temperature & \multirow{2}{*}{ text } & \multirow{2}{*}{$\begin{array}{c}\text { Chinese } \\
\text { meteorologica } \\
\text { 1 science data }\end{array}$} \\
\hline & precipitation & & \\
\hline \multirow{3}{*}{$\begin{array}{l}\text { vegetation } \\
\text { data }\end{array}$} & NPP & $\begin{array}{l}\text { hdf } \\
(1 \mathrm{~km})\end{array}$ & $\begin{array}{c}\text { MODIS } \\
\text { MOD17A3 }\end{array}$ \\
\hline & NDVI & $\begin{array}{l}\text { geotiff } \\
(250 \mathrm{~m})\end{array}$ & $\begin{array}{c}\text { MODIS } \\
\text { MOD13Q1 }\end{array}$ \\
\hline & $\begin{array}{l}\text { geographic } \\
\text { census data }\end{array}$ & vector & $\begin{array}{c}\text { National } \\
\text { geographic } \\
\text { census data in } \\
2016\end{array}$ \\
\hline soil data & soil data & $\begin{array}{l}\text { grid } \\
(1 \mathrm{~km})\end{array}$ & $\begin{array}{l}\text { The second } \\
\text { national soil } \\
\text { survey }\end{array}$ \\
\hline land use data & land use data & vector & $\begin{array}{l}\text { National land } \\
\text { use change } \\
\text { survey data }\end{array}$ \\
\hline
\end{tabular}

Table 1. The types and sources of data

We integrate these data into the same scale of $250 \mathrm{~m}$. Since the dada formats are different, vector data is converted to raster image and temperature as well as precipitation raster image data with spatial resolution $250 \mathrm{~m}$ is generated by kriging interpolation method. NPP and soil data are up sampling with bilinear 
interpolation, one of the basic resampling techniques, to spatial resolution of $250 \mathrm{~m}$. Meanwhile, DEM data is down-sampling to $250 \mathrm{~m}$ using bilinear interpolation.

\subsection{Methods}

According to the main characteristics of ecosystem services and regional ecological sensitivity in Fujian province, using the quantifying index method, we evaluate the ecological protection level of Fujian province through assessing the ecosystem services function level and ecological sensitivity level, among which the ecosystems service function includes biodiversity protection function, soil conservation function and water conservation function, while ecological sensitivity mainly includes soil and water loss sensitivity. The flowchart of the assessment method is shown in Figure2.

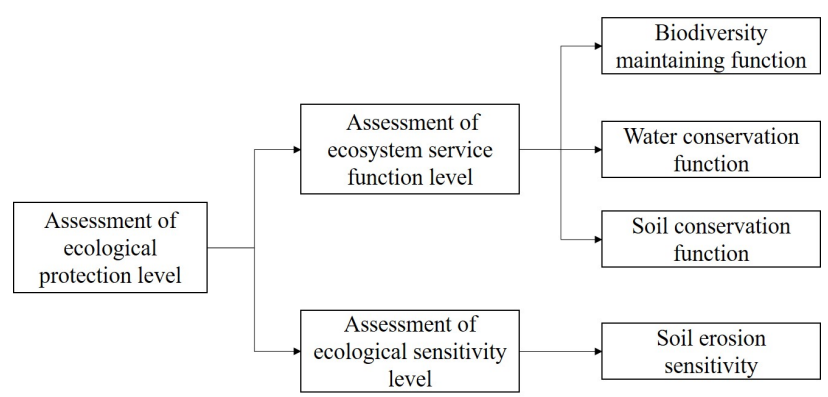

Figure2. Flowchart of the assessment method

\subsubsection{Biodiversity Maintaining Function}

$$
S_{\text {bio }}=N P P_{\text {mean }} \times F_{\text {pre }} \times F_{\text {temp }} \times\left(1-\mathrm{F}_{\text {alt }}\right)
$$

where $N P P_{\text {mean }}$ is the mean value of NPP from 2000 to 2015 , $F_{\text {pre }}, F_{\text {temp }}, F_{\text {alt }}$ represent mean precipitation, mean air temperature, and altitude which are normalized to $[0,1]$.

\begin{tabular}{|c|c|c|}
\hline Code & Land cover type & Coefficient \\
\hline $310-313$ & $\begin{array}{c}\text { arboreal forest } \\
\text { broad leaved forest } \\
\text { coniferous forests } \\
\text { mixed broadleaf-conifer } \\
\text { forest }\end{array}$ & 1 \\
\hline $\begin{array}{c}320- \\
350 / 411 / 1001\end{array}$ & $\begin{array}{c}\text { shrub wood } \\
\text { mixed arboreal shrubby } \\
\text { forest } \\
\text { bamboo forest } \\
\text { open forest } \\
\text { high-coverage grassland }\end{array}$ & 0.8 \\
\hline $360-380$ & $\begin{array}{l}\text { young plantation } \\
\text { open shrublands }\end{array}$ & 0.6 \\
\hline $\begin{array}{c}210-291 / 412 \\
413 / 421- \\
429 / 1012\end{array}$ & $\begin{array}{l}\text { garden } \\
\text { grass land with low and } \\
\text { middle coverage }\end{array}$ & 0.4 \\
\hline $110 / 120$ & farmland & 0.2 \\
\hline $500-800$ & buildings and roads & 0.01 \\
\hline
\end{tabular}

Table 2. Assignment of "species habitat factors" coefficient
Considering that the original spatial resolution of NPP is $1 \mathrm{~km}$, and precipitation and air temperature are spatially interpolated data, the spatial accuracy of the results is insufficient, and the vertical zonation of vegetation is not presented well. According to topographic features of Fujian province, "species habitat factors" is introduced to revise the equation. The correction method is to multiply the calculation result of equation (1) by the "species habitat factor" coefficient, as shown in Table 2 which is assigned according to the current vegetation conditions of the 2016 national geographic census land cover classification. The coefficient is given with the combination of reference to literature (Fan, 2019) and the characteristics of spatial distribution of land use in Fujian province.

\subsubsection{Water Conservation Function}

$$
S_{\text {wat }}=N P P_{\text {mean }} \times F_{\text {sic }} \times F_{\text {pre }} \times\left(1-F_{\text {slo }}\right)
$$

where $F_{\text {sic }}$ is the soil infiltrating capacity factor and $F_{\text {slo }}$ represents slope which is normalized to $[0,1]$.

With the same considerations as the assessment of the biodiversity maintaining functions, the "land cover factor" and "altitude factor" are introduced to correct the evaluation results. The correction method is to multiply the calculation result of equation (2) by the "land cover factor" coefficient, as shown in Table 3 and "altitude factor" coefficient.

The "altitude factor" plays a prominent role in a mountainous area with water conservation function. The "altitude factor" coefficient is calculated as

$$
\operatorname{ALT}=\operatorname{Max}\left(H_{i}, H_{v e g}\right) / H_{\max }
$$

where $H_{i}$ is the elevation value of the pixel, $H_{\max }$ is the maximum altitude of study area and $H_{\text {veg }}$ is the elevation value of the vegetation with the largest distribution area in the vertical zone vegetation in the study area. In Fujian province, the most widely distributed vegetation is coniferous forest, so $H_{v e g}$ is the altitude value of coniferous forest with maximum distribution area.

\begin{tabular}{ccc}
\hline Code & Land cover type & Coefficient \\
\hline arboreal forest \\
broad leaved forest \\
coniferous forests \\
mixed broadleaf-conifer \\
forest \\
bamboo forest \\
water \\
Shrub wood \\
320/330/350/380/ & 0.9 \\
411 & $\begin{array}{c}\text { mixed arboreal shrubby } \\
\text { forest } \\
\text { open forest } \\
\text { high-coverage grassland } \\
\text { young plantation } \\
\text { grass land with low and } \\
\text { middle coverage } \\
\text { artificial grassland } \\
\text { garden } \\
\text { farmland } \\
\text { desert }\end{array}$ & 0.7 \\
$100 / 370 / 412 / 413 / 1000$ & 0.5 \\
$500-800$ & buildings and roads & 0.3 \\
\hline
\end{tabular}

Table 3. Assignment of "land cover factor" coefficient 
Similar to "species habitat factors" coefficient, we set "land cover factor" coefficient considering the current situation of land cover in Fujian province and expert marking (Fan, 2019).

\subsubsection{Soil Conservation Function}

$$
S_{\text {pro }}=N P P_{\text {mean }} \times(1-K) \times\left(1-F_{\text {slo }}\right)
$$

where $\mathrm{K}$ denotes soil erodibility factor.

2.3.4 Soil Erosion Sensitivity: Using the areas where soil erosion occurred in Fujian province in 2015 as training samples, a softmax regression model is used to establish linear regression relationship between soil erosion sensitivity level and four factors: rainfall erosion, vegetation coverage, topographic relief, and soil erodibility. The model predicts the sensitivity level of soil erosion.

Based on the methods presented above, we calculate the ecosystem services function and ecological sensitivity. Then the results of ecosystem services function are evaluated as three levels, namely extremely important, very important and important, corresponding to $30 \%, 70 \%$, and $100 \%$ of the cumulative service value.

Then, the layers of results of ecological service function, i.e., biodiversity maintaining function, soil conservation function and

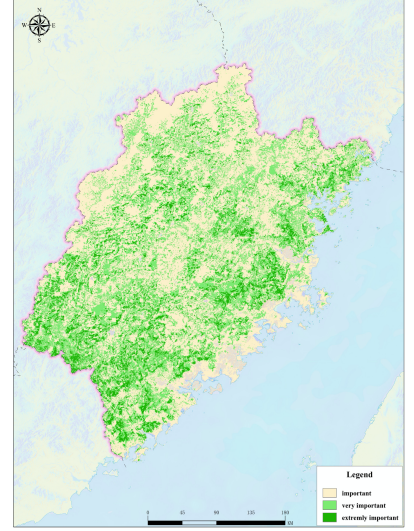

a. Biodiversity protection function level

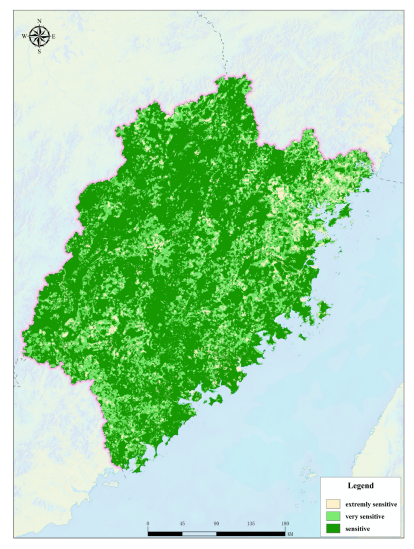

e. Soil erosion sensitivity level

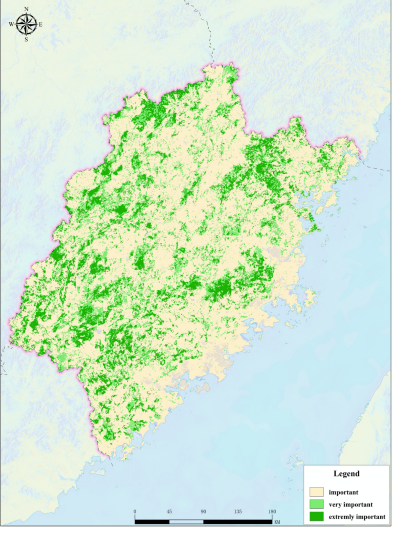

b. Water conservation function level

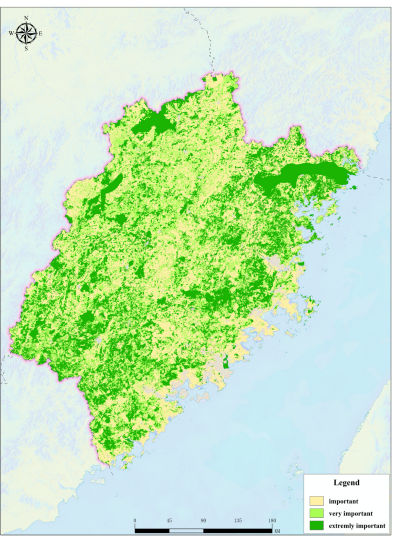

f. Ecological protection level

water conservation function, are overlapped and the maximum level of each pixels in the three layers is as the evaluation result of ecosystem services function. Next, we take the maximum value of ecosystem services function level and ecological sensitivity level as the initial ecological protection level. Then we use the existing nature reserves, national forest parks, Wuyi Mountain forest park, national wetland parks, and national geological parks of Fujian province to revise the initial result.

\section{RESULTS AND DISCUSSION}

With regard to the biodiversity protection assessment result, the extremely important area is $12,237.08 \mathrm{~km} 2$, accounting for $10.16 \%$ of the total area of Fujian province, and the very important area is $47,348.58 \mathrm{~km} 2$, occupying $39.33 \%$ the study area (Figure 3a).

As for the evaluation results of water conservation (Figure $3 b$ ), the extremely important and very important area is $16,510.49$ and $24,205.32 \mathrm{~km} 2$, respectively, making up $13.71 \%$ and $20.10 \%$ of Fujian province. As regards the soil conservation evaluation result (Figure 3c), there are 15,351.48 $\mathrm{km} 2$ of extremely important areas and $29,543.77 \mathrm{~km} 2$ of very important areas, accounting for $12.75 \%$ and $24.54 \%$ of the study area respectively.

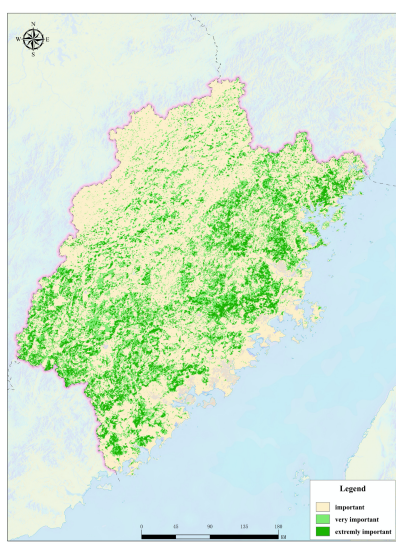

c. Soil conservation function level

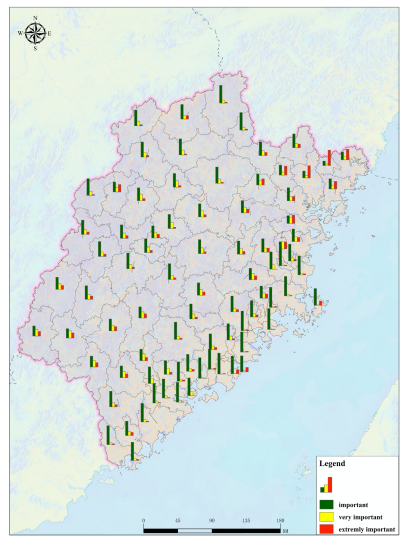

g. Comparison of area of farmland and ecological protection level

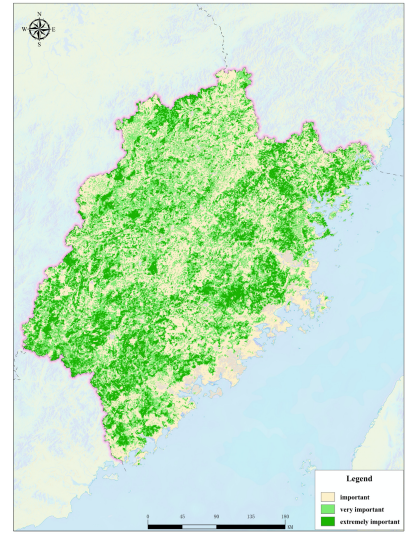

d. Biosystem service function level

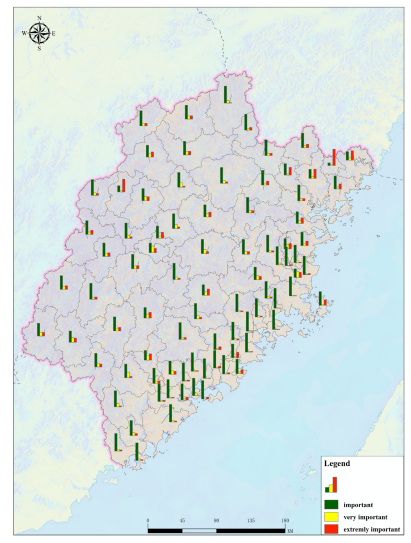

h. Comparison of area of construction land and ecological protection level

Figure3. The evaluation and spatial distribution of ecological protection level 


\begin{tabular}{|c|c|c|c|c|c|c|}
\hline Level & \multicolumn{2}{|c|}{ Important } & \multicolumn{2}{c|}{ Very important } & \multicolumn{2}{c|}{ Extremely important } \\
\hline City & Area $\left(\mathrm{km}^{2}\right)$ & Percentage (\%) & Area $\left(\mathrm{km}^{2}\right)$ & Percentage (\%) & Area $\left(\mathrm{km}^{2}\right)$ & Percentage (\%) \\
\hline Quanzhou & 4889.43 & 47.52 & 3182.93 & 30.93 & 2217.42 & 21.55 \\
\hline Fuzhou & 3903.81 & 36.02 & 3253.52 & 30.02 & 3887.14 & 35.86 \\
\hline Putian & 1371.85 & 38.49 & 877.68 & 24.62 & 1314.89 & 36.89 \\
\hline Zhangzhou & 4525.22 & 36.33 & 3985.66 & 32.00 & 3945.82 & 31.68 \\
\hline Ningde & 3684.12 & 28.46 & 3034.56 & 23.44 & 6226.13 & 48.10 \\
\hline Xiamen & 532.27 & 48.45 & 211.33 & 19.24 & 355.03 & 32.32 \\
\hline Nanping & 11285.05 & 41.79 & 9720.20 & 36.00 & 5996.36 & 22.21 \\
\hline Sanming & 9289.41 & 39.26 & 8647.83 & 36.55 & 5724.19 & 24.19 \\
\hline Longyan & 4981.35 & 25.49 & 7094.83 & 36.30 & 7467.71 & 38.21 \\
\hline
\end{tabular}

Table 4. The statistics of ecological protection level in Fujian province

Through the raster calculation of the above-mentioned three kinds of ecosystem service function assessment results, the ecosystem service level is obtained (Figure 3d). The extremely important area is $28,165.04 \mathrm{~km}^{2}$, making up $23.39 \%$ of the study area, and the very important area is $44,440.13 \mathrm{~km}^{2}$, accounting for $36.91 \%$ of the area of Fujian province. The evaluation results of soil erosion sensitivity in Fujian province (Figure 3e) show that there is a possibility of soil erosion, since the area of extremely sensitive area is $8,208.54 \mathrm{~km}^{2}$, and the area of very sensitive area is $31,352.28 \mathrm{~km}^{2}$, occupying $6.82 \%$ and $26.04 \%$ of Fujian province.

After combining and analysing the extremely important and very important area of ecosystem service function evaluation map, and the extremely sensitive and very sensitive area of the soil erosion sensitivity assessment results, the ecological protection level map of Fujian province is obtained (Figure 3f). Based on the comprehensive evaluation, the area of extremely important ecological protection in Fujian province is $36834.81 \mathrm{~km}^{2}$, accounting for $30.59 \%$ of the total study area. It is mainly distributed in the Wuyi Mountain area in northwest, the Jiu Peak area and Gutian Reservoir area in the north, the Taiyu Mountain area in the northeast, Baishi Peak area and Jinxi area in the west, Daiyun Mountain area in the middle, and Lao Mountain area in the southwest. Besides, the very important ecological protection area is $39,431.97 \mathrm{~km}^{2}$ and the important area is $44,133.22 \mathrm{~km}^{2}$, making up $32.75 \%$ and $36.66 \%$ of the total area of Fujian province.

The proportion of extremely important level of ecological protection areas in nine cities of Fujian province ranges from $21.55 \%$ to $48.10 \%$, as shown in Table 4 . There are 4 cities, i.e., Ningde, Longyan, Putian, and Fuzhou, having more than 35\% area that is the most important ecological protection area, as shown in Table 4 . The extremely important ecological protection areas of 84 districts account for $2.70 \% \sim 78.48 \%$, with a large difference, which reflects the imbalance of ecological background. There are 7 districts that have more than $50 \%$ area are the extremely important ecological protection area, which are Zherong, Fu'an, Zhouning, Fuding, Jimei, Xiapu, Jin'an. Except the 9 districts, there are 16 counties with more than $40 \%$ of the extremely important ecological protection area.

The land use classification map is overlain on the evaluation results of ecological protection map, and the spatial relationship between farmland and construction land, and ecological protection extremely important areas is analysed, respectively (Figure 3g, Figure 3h, Table 5, Table 6). The area of farmland within the area of ecological extremely important protection is
$2,191.56 \mathrm{~km}^{2}$, which accounts for $14.44 \%$ of the total farmland area. The districts with a large proportion of cultivated land within ecological extremely important areas are Zherong, Fu'an, Fuding, Zhouning, Pingnan, Taining, and Xiapu. The main reason is that these farmland areas distributed in national geological parks with area of $438.77 \mathrm{~km}^{2}$. We suggest that the government should investigate why there is such a large amount of cultivated land in the geopark, and then decide how to deal with the farmland. The proportion of cultivated land within the ecological extremely important areas of Luoyuan and Jin'an is relatively large, mainly due to the fact that some cultivated land is in the extremely important water conservation area and biodiversity preservation area. We advise that the soil nutrients and organic matter content in these areas should be surveyed. Based on the surveying results of the quality of soil, the government could decide whether to choose ecological defarming policy or modify the boundary of the most important ecological protection area.

\begin{tabular}{ccc}
\hline Level & Area $\left(\mathrm{km}^{2}\right)$ & Percentage (\%) \\
\hline Extremely important & 2191.56 & 14.44 \\
Very important & 3072.92 & 20.25 \\
Important & 9910.03 & 65.31 \\
\hline
\end{tabular}

Table 5. Comparison of ecological protection level evaluation results and farmland area

\begin{tabular}{ccc}
\hline Level & Area $\left(\mathrm{km}^{2}\right)$ & Percentage (\%) \\
\hline Extremely important & 542.65 & 12.94 \\
Very important & 456.39 & 10.89 \\
Important & 3193.15 & 76.17 \\
\hline
\end{tabular}

Table 6. Comparison of ecological protection level evaluation results and construction land area

The area of construction land within the extremely important ecological protection area is $542.65 \mathrm{~km}^{2}$, making up $12.94 \%$ of the total construction land area, as shown in Figure $3 \mathrm{~h}$. The districts with a large proportion include Zherong, Taining, Fuding, Fu'an, and Zhouning. In these areas, some towns and villages are located in geological parks. Therefore, demarcating ecological protection red line may conflict with development planning of local government. How to resolve this contradiction in land use is directly related to the final demarcation of the ecological protection red line. In other areas, the proportion of 
the building area within the ecological extremely important area is relatively low. through spatial analysis, we find that most of the construction area overlapping with the most important ecological protection area are very fragmented. We think field survey should be carried out to determine the ecological boundaries of these fragments in map.

\section{CONCLUSION}

Ecological protection red line is a new concept proposed by China in recent years, and there are few studies on theories and methods. This paper refers to the existing research results of the "Guidelines for the Delineation of Ecological Red Lines" and the "Assessment Guidelines for the Carrying Capacity of Natural Resources and the Suitability of Territorial development". We use quantifying index method, specifically the ecosystem service function evaluation methods and ecological sensitivity evaluation methods, to assess the ecological protection level of Fujian Province. The extremely important area is $37,134.68 \mathrm{~km}^{2}$, accounting for $30.59 \%$ of the total area. However, it is limited by research theories, methods, and data. Only ecosystem service functions such as biodiversity, soil conservation, and water conservation are considered, as well as soil erosion sensitivity. Other ecosystem service functions and ecological sensitivity effects need to be further studied.

The evaluation method of this study still needs improvement. First, the biodiversity assessment cannot identify the habitats of rare species accurately, and more long-term field monitoring site data needs to be obtained. Second, in the biodiversity preservation function assessment and the water conservation function evaluation, the accuracy of the NPP data is not sufficient. The national geographic census data is used to revise the evaluation method. Last, after evaluating the ecological protection level at the provincial scale, it is necessary to carry out the verification at the district and county scale to verify the rationality of the results.

\section{ACKNOWLEDGEMENTS}

This research was funded by the National Natural Science Foundation of China (Grant No. 41901310) and Geological Survey Project of China (Grant No.DD20190301).

\section{REFERENCES}

Ding Yuchen, Feng Changchun, Wang Liwei. The method and empirical study of the land ecological red line in the mountainous region: A case study of Yihe town in Chongqing Municipality. Progress in Geography, 2016, 35(7): 851-859

Fan Jie. Assessment guidelines for resource and environmental carrying capacity and territorial development suitability. Science Press, 2019.

Jiang Dalin, Cao Xiaofeng, Kuang Honghai, et al. Analysis on the key problems of the red line of ecological protection and its demarcation. Resources Science, 2015, 37(9): 1755-1764.

Hu, Tian, Peng, Jian, Liu, Yanxu, et al. Evidence of green space sparing to ecosystem service improvement in urban regions: A case study of China's Ecological Red Line policy. Journal of Cleaner Production, 2020, 251: 119678.

Liu Shengcheng. Research on urban ecological red line planning methods. Shanghai Urban Planning Review, 2012, (6): 24-29.
Ministry of Environmental Protection. Guidelines for the delineation of the red line for ecological protection (Eco group of the office of the Ministry of Environmental Protection [2017]48th). http://www.zhb.gov.cn/gkml/hbb/bgt/201707/ t201 70728_418679.htm, 2017-07-20.

Yan Shouguang, Lin Naifeng, Shen Weishou. Regional division and protection of ecological red line in Jiangsu province. Journal of Ecology and Rural Environment, 2014, 30(3): 294-299.

Yang Shanshan, Zou Changxin, Shen Weishou, et al. Construction of ecological security pattern based on ecological red line division: Taking Jiangxi province as an example. Chinese Journal of Ecology, 2016, 35(1): 250-258.

Yu Kongjian, Wang Sisi, Li Dihua, et al. The function of ecological security patterns as an urban growth framework in Bejing. Acta Ecologica Sinica, 2009, 29(3): 1189-1204.

Zeng Congsheng. Investigation Report on the Present Situation of Ecological Environment in Fujian. Beijing: China Environmental Science Press, 2003.

Zhang Xuefei, Wang Chuansheng, Li Meng. Demarcating ecological space and ecological protection red line under the framework of territory spatial planning. Geographical Research, 2019, 38 (10): 2430-2446. 